\title{
Manufacturing of Fire Resistance Geopolymer: A Review
}

\author{
Ikmal Hakem Aziz ${ }^{1, *}$, Mohd Mustafa Al Bakri Abdullah ${ }^{2}$, Heah Cheng Yong ${ }^{1}$, Liew Yun \\ Ming $^{1}$, Kamarudin Hussin ${ }^{1,2}$, Aeslina Abdul Kadir ${ }^{3}$ and Emy Aizat Azimi ${ }^{1}$ \\ ${ }^{1}$ Center of Excellence Geopolymer and Green Technology, School of Materials Engineering, \\ Universiti Malaysia Perlis (UniMAP), P.O. Box 77, D/A Pejabat Pos Besar, 01000, Kangar, Perlis, \\ Malaysia \\ ${ }^{2}$ Faculty of Engineering Technology, Universiti Malaysia Perlis (UniMAP), P.O. Box 77, D/A \\ Pejabat Pos Besar, Kangar, Perlis 01000, Malaysia \\ ${ }^{3}$ Department of Water and Environmental Engineering, Faculty of Civil and Environmental \\ Engineering, University Tun Hussein Onn Malaysia, Batu Pahat Johor, Malaysia
}

\begin{abstract}
Protection against fire using inorganic polymer is a new application of engineering technology. Even though, there are varieties of fire-protection materials, there is always a need for the development of new materials with improved thermophysical properties and low cost. Geopolymer composites materials are promising from this point of view. Granulated blast furnace slag, boiler ash and fly ash have been used as the prime materials for forming geopolymers composites. Geopolymers have been studied due to its unique properties such as a good fire resistance. Geopolymer offers an innovative for application associated with the high thermal application. This paper summarizes on the potential of alkaliactivated materials over the past decades along with outlines of the manufacturing of geopolymer composites for fire resistance application.
\end{abstract}

\section{Introduction}

Ordinary Portland cement (OPC) is the topmost volume engineering materials in use today. It has been used as a binding agent for concrete due to its exceptional thermal performance, mechanical properties and durability [1]. However, there is an argument in environmental issues on the enormous energy consumption and emissions of carbon dioxide (CO2) during its manufacture [2].The manufacturing of concrete in industry is one of the major contributors of the global warming. It has been reported that 13,500 million tons of $\mathrm{CO} 2$ are produced from the process worldwide, accounting approximately $7 \%$ of the annually produced greenhouse gases [3]. Practically, geopolymers are increasing interest as ecologically friendly fireproof building materials, sound heat insulators, materials for encapsulating hazardous wastes and low energy consumption during production from raw materials $[4,5]$. Geopolymer are well known as having great properties including high

\footnotetext{
*Corresponding author: ikmalhakem@gmail.com
} 
compressive strength, high temperature stability, low thermal conductivity, and high thermal engineering applications [6-8].

Thermal conductivity, strength retention after heat treatment, non combustibility, and temperature capability are used as indicators for fire endurance of geopolymer materials. Geopolymer has been proposed for very good heat resistance having thermal stability up to $800-1200^{\circ} \mathrm{C}$ [9]. Nevertheless, it is reported that geopolymers panels made of granulated slag filler and metakaolin exhibited an improved fire resistance behavior. The temperature on the cold side of the panels was $350^{\circ} \mathrm{C}$ after exposure up to $1100^{\circ} \mathrm{C}$ for 35 min [10]. Others, Zhang et al. [9] found that geopolymer derived from alkali activation showed excellent strength retention after heating to temperature from 100 to $800^{\circ} \mathrm{C}$, and the postcooling compressive strength increased by as much as $100 \%$ after exposure $800^{\circ} \mathrm{C}$ due to densification and phase transformation as shown in Figure 1. This paper review demonstrate that geopolymer composites are promising fire resistance material for engineering applications.

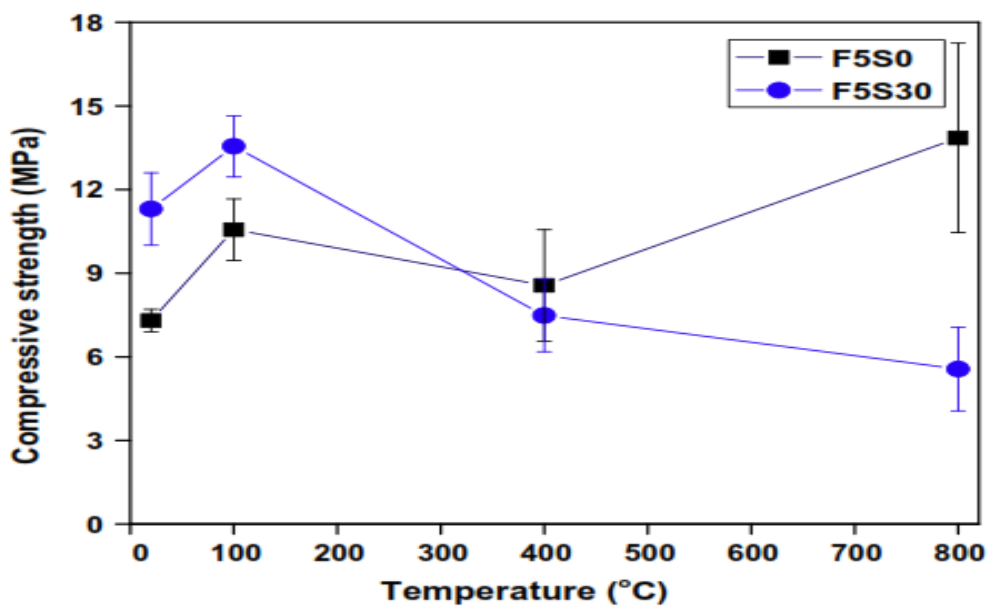

Fig. 1. Compressive strength of Geopolymer after exposure to different temperature [9].

\section{Sources materials}

Granulated blast furnace slag (GBFS) potential industrial waste used as raw material in geopolymerization process. Based on the study by Khale et al. [11], slag containing a wide range of natural Al-Si minerals, could be developed as potential sources materials for the synthesis of geopolymers. The chemical composition of the slag materials is shown in Table 1 which demonstrates major composition in the source material of geopolymer is $\mathrm{SiO} 2$.

Table 1. XRF analysis data of Blast furnace slag and boiler slag composition [12, 13].

\begin{tabular}{|c|c|c|c|c|c|c|c|}
\hline Materials & $\mathbf{S i O}_{2}$ & $\mathbf{A l}_{\mathbf{2}} \mathbf{O}_{\mathbf{3}}$ & $\mathbf{F e}_{\mathbf{2}} \mathbf{O}_{\mathbf{3}}$ & $\mathbf{\mathbf { T i O } _ { 2 }}$ & $\mathbf{C a O}$ & $\mathbf{M g O}$ & $\mathbf{N a}_{2} \mathbf{O}$ \\
\hline $\begin{array}{c}\text { Blast } \\
\text { Furnace } \\
\text { Slag }\end{array}$ & 34.39 & 14.47 & 0.63 & 0.53 & 41.6 & 6.49 & 0.22 \\
\hline $\begin{array}{c}\text { Boiler } \\
\text { Slag }\end{array}$ & 49.29 & 25.39 & 7.65 & N/A & 0.63 & 0.53 & N/A \\
\hline
\end{tabular}


Fly ash also becomes another potential waste material that contains a high percentage of amorphous silica and alumina precursors [14]. Geopolymerization process with fly ash happened via a mechanism involving the dissolution of aluminum and silicon species from the surface of fly ash as the surface hydration of undissolved waste particles, the polymerization of active group, gel formation and subsequently hardening of geopolymer structure [15]. Table 2 present one of the general chemical composition of fly ash obtained by XRF analysis.

Table 2. XRF analysis data of fly ash composition [16].

\begin{tabular}{|c|c|}
\hline Chemical & Fly ash \\
\hline $\mathrm{SiO}_{2}$ & $52.11 \%$ \\
\hline $\mathrm{Al}_{2} \mathrm{O}_{3}$ & $23.59 \%$ \\
\hline $\mathrm{Fe}_{2} \mathrm{O}_{3}$ & $7.39 \%$ \\
\hline $\mathrm{TiO}_{2}$ & $0.88 \%$ \\
\hline $\mathrm{CaO}$ & $2.61 \%$ \\
\hline $\mathrm{MgO}$ & $0.78 \%$ \\
\hline $\mathrm{Na}_{2} \mathrm{O}$ & $0.42 \%$ \\
\hline
\end{tabular}

\section{Alkaline solution}

The fundamental of geopolymerization are the dissolution of solid aluminosilicate oxide M$\mathrm{OH}$ solution where $\mathrm{M}$ is the class of alkali metal ( mostly $\mathrm{Na}$ and $\mathrm{K}$ ), dissolution of dissolved $\mathrm{Al}$ and $\mathrm{Si}$ complexes to an inter-particle space, then the formation of a gel phase by polymerization between silicate solution and $\mathrm{Al}$ and $\mathrm{Si}$ complexes, and the hardening formed in gel phase at the finishing steps [17]. The mixture of sodium hydroxide $(\mathrm{NaOH})$ and sodium silicate $(\mathrm{Na} 2 \mathrm{SiO} 3)$ is the alkaline solution that often used [18]. Alkali hydroxide is needed for the dissolution of aluminosilicate sources while sodium silicate solution acts as a binder, plasticizer and alkali activator [19]. Alkaline solution also encourages a few amount of $\mathrm{Si}$ and $\mathrm{Al}$ atoms to dissolve the aluminosilicate sources from monomer in solutions, and then polycondense to form a rigid framework [20]. The rate of polymerization reaction increases as the sodium silicate is the preferred activating solution owing to its soluble silicate content. The specific surface composition of the initial raw materials, the composition, type, and quantity of alkali activator influencing the properties of geopolymers [21]. Besides, the various ratios of solid-to-liquid (S/L) ratio and Na2SiO3to- $\mathrm{NaOH}$ ratio have significant effect on compressive strength [22].

\subsection{Geopolymerization reaction and mechanism}

Geopolymerization is a complex process and it is involving three steps as shown in Figure 2; (Eq.1) dissolution in alkaline solution; (Eq.2) reorganization and diffusion of dissolved ions with formation of small coagulated structures; (Eq.3) polycondensation of soluble species to form hydrated products [6-7,19]. A chemical reaction covering the polycondensation of orthosialiate (hypothetical monomer) that proposed by Davidovits [23]. 


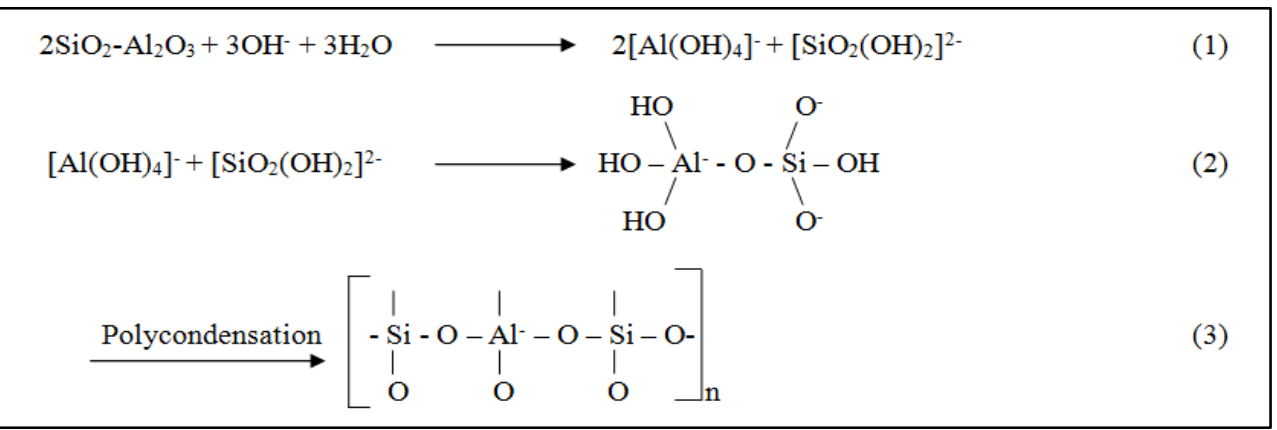

Fig. 2. Three steps of geopolymerization process [19].

\subsection{Manufacturing geopolymer}

Figure 3 presents the steps in manufacturing of geopolymer. There are involving a few technological parameters to achieve their certain properties of geopolymer such as fire resistance. Practically, the mixing of concentrated aqueous alkali hydroxide or silicate solution with solid aluminosilicates form a synthetic alkali aluminosilicates. Furthermore, filler may add in the preparing of geopolymer materials in order to achieve the required properties. Temuujin et al. [24] conducted research on the calcining of metakaolin at temperature $750^{\circ} \mathrm{C}$ for 24 hours. The calcined kaolin with the composition of Si:Al ratio 2.5 and $\mathrm{Na}: \mathrm{Al}$ ratio of 1 was prepared as the optimum ratio to produce geopolymer. Water acts as an additional factor on the preparing of geopolymer material. The unexpected expansion with temperature of MK 2.5 provided a level of matching with the thermal expansion of the substrate resulting in the maintenance of the structural integrity of the resulted product. Calcining of bulk geopolymer with $\mathrm{Si}$ : $\mathrm{Al}=2.5$ to $1000^{\circ} \mathrm{C}$ resulted in formation of sodium aluminosilicate.

Mustafa et al. [25] study on fly ash based geopolymer for coating application at high temperature. The fly ash geopolymer coating was prepared by mixing alkaline activator solution $12 \mathrm{M} \mathrm{NaOH}$ with the aluminosilicates. The ratio of fly ash/alkaline activator to $\mathrm{Na} 2 \mathrm{SiO} / \mathrm{NaOH}$ was standardized at 2.5. After compounding process, the slurry paste formed then applied to ceramic substrate by dipping method with the coating thickness ranging between $0.3-05 \mathrm{~mm}$. The ceramic plates were cured at $70^{\circ} \mathrm{C}$ for 24 hours. In order to improve thermal properties and strength of the obtained geopolymer, samples was sintered for 3 hours at temperature ranged between $600^{\circ} \mathrm{C}$ and $1500^{\circ} \mathrm{C}$ with heating and cooling rates $5^{\circ} \mathrm{C} / \mathrm{min}$. The result obtained that the highest compressive strength of $40 \mathrm{MPa}$ improve proportional with the sintering temperature, $1500^{\circ} \mathrm{C}[25]$. 


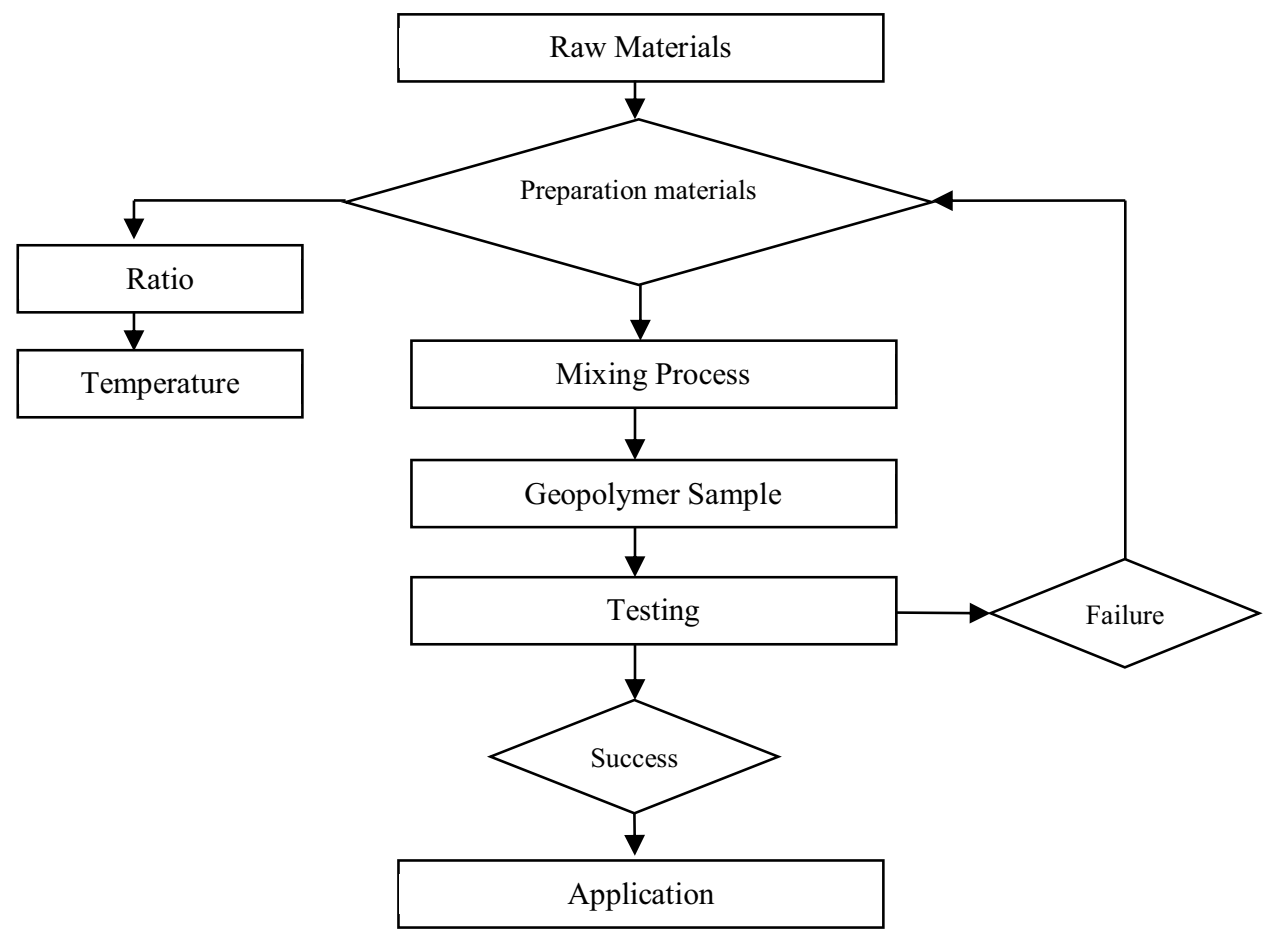

Fig. 3. General process in manufacturing of geopolymer

\section{Conclusion}

This paper summarized the manufacturing of geopolymer material for fire resistance applications. Furthermore, geopolymer consists great mechanical and physical properties which offer economic and environmental friendly as an alternative to Ordinary Portland cement (OPC). There is not much study being carried out on the application of geopolymer material at high temperature. Thus, the development of geopolymer for future research in this field will lead a new era of material engineering in fire fighting/ safety precautions area.

The authors gratefully acknowledge Center of Excellence Geopolymer and Green Technology (CEGeoGTech) and School of Materials Engineering, UniMAP for their expertise and support. The authors would also like to thank for the funding support from the Fundamental Research Grant Scheme (FRGS-9003-00540) under Ministry of Education Malaysia (MOE).

\section{References}

1. H. Djwantoro, E.W. Steenie, M.J.S. Dody, B.Vijaya Rangan, Aci. Mater. J., 101(6), 467 (2004)

2. V. Malhotra, Advances in Concrete Technologies in the Middle East, (2008)

3. A.M. Mustafa Al Bakria, H. Kamarudin, M. BinHussain, I. Khairul Nizar, Y. Zarina, A.R. Rafiza, Physics Procedia, 22, 286 (2011)

4. R.E. Lyon, P.N. Balaguru, A. Foden, U. Sorathia, J. Davidovits, M. Davidovics, Fire Mater., 21(2), 67 (1997) 
5. H. Khater, MATEC web conf., 11, (2014)

6. D. Dimas, I. Giannopoulou, D. Panias, J. Mater. Sci., 44(14), 3719 (2009)

7. S. Alonso, A. Palomo, Cement Concrete Res., 31(1), 25 (2001)

8. Y.J. Zhang, Y.C. Wang, S. Li, Mater. Sci. Eng., 527(24), 6574 (2010)

9. Z. Zhang, J.L. Provis, A. Reid, H. Wang, Cement Concrete Comp., 62, 97 (2015)

10. L. Vickers, A. Van Riessen, W.D.A Rickard, Fire-Resistant Geopolymers: Role of Fibres and Fillers to Enhance Thermal Properties, (Springer 2015)

11. D. Khale, R. Chaudhary, J. Mater. Sci., 42(3), 729 (2007)

12. T. Cheng, J. Chiu, Miner. Eng., 16(3), 205 (2003)

13. M.A. Villaquiran-Caicedo, R.M. de Gutierrez, S. Sulekar, C. Davis, J.C. Nino, Appl. Clay Sci., 118, 276 (2015)

14. U. Rattanasak, P. Chindaprasirt, Miner. Eng., 22(12), 1073 (2009)

15. H. Xu, J. Van Deventer, G. Lukey, Ind. Eng. Chem. Res., 40(17), 3749 (2001)

16. M. Al Bakri, A. Mohd, H. Kamarudin, O.A. Abdulkareem, C.M.R. Ghazali, A.R. Rafiza, M.N. Norazian, Applied Mechanics and Materials, 110, 734 (2012)

17. Y.M. Liew, H. Kamarudin, A.M. Mustafa Al Bakri, M. Binhussain, M. Luqman, I. Khairul Nizar, C.M. Ruzaidi, C.Y. Heah, Phys Procedia, 22, 312 (2011)

18. N. Lloyd, B. Rangan, $2^{\text {nd }}$ International Conference On Sustainable Construction Materials And Technologies, Ancona, Italy, (2010)

19. K. Komnitsas, D. Zaharaki, Miner. Eng., 20(14), 1261 (2007)

20. H. Kamarudin, Y.M. Liew, A. Mohd Mustafa Al Bakri, M. Luqman, I. Khairul Nizar, C.Y. Heah, Aust. J. Basic \& Appl. Sci., 5(9), 441 (2011)

21. P. Rovnanik, Constr. Build Mater., 24(7), 1176 (2010)

22. D.L. Kong, J.G. Sanjayan, K. Sagoe-Crentsil, Cement Concrete Res., 37(12), 1583 (2007)

23. J. Davidovits, J. Therm. Anal. Calorim., 37, 1633 (1991)

24. J. Temuujin, W. Rickard, M. Lee, A. Van Riessen, J. Non-Cryst. Solids, 357(5), 1399 (2011)

25. A.M.A.B. Mohd, L. Jamaludin, K. Hussin, M. Binhussain, C.M.R. Ghazali, A.M. Izzat, Adv. Mat. Res., 686, 227 (2013) 